\title{
In Vitro City: A Laboratory without Experiments
}

\author{
SEVERINO ALFONSO \\ Universidad Politécnica de Madrid
}

\author{
LOUKIA TSAFOULIA \\ City College of New York
}

\begin{abstract}
The paper states the relationships between the instrumentality of building systems, the aesthetics and politics of software and the digital technologies impact on the built environment. It explores the space between the architect's intentionality and the changing modes in architectural production. The text proposes a critical awareness of the epistemological and technical dimension of the digital instruments as a way for architects to better appropriate the expanding array of digital tools in an ever-increasing urban complexity.
\end{abstract}

In The Alphabet and the Algorithm ${ }^{1}$ and the Digital Turn, ${ }^{2}$ Mario Carpo establishes three phases that aim to structure the changes that architecture has undergone during the ubiquitous implementation of the digital technologies in the design production. The first phase is related to Form where he comments on the alterations that have affected digital morphologies in architecture. The second relates to Process and regards to the decision-making strategies in the architectural project. And the last is on Agency where he investigates the generative transformations behind the collective identity in the design field.

Also, in his article The Craftsman and the Curator ${ }^{3}$ from 2011, Carpo resumes a series of interesting points closely related to these principles. In the article, he first establishes a maxim studied by scholars during the last two decades as he recognized the contemporary production actuality that "unlike a building that is a physical object, the architectural design is pure information." ${ }^{4} \mathrm{~A}$ statement that has strong implications to the design community but is yet to be entirely assimilated. Second, he refers to the direct correlation between digital design and the customization processes. These being possible by new digital manufacturing techniques starting their implementation in the mid-1990s by architects such as Gregg Lynn, Bernard Cache or John Frazer among others, and gaining exponential presence up to today. In this regard, he also comments on the slow integration of the economic absorption associated with the mass customization in the architecture construction in general. And in doing so, he questions if this shift follows the needs and demands of the consumer. A third highlight and one of importance to this text is found in his reference to a shifting and constantly changing character that defines the digital technologies. According to Carpo, these are "rickety -not by dint of clockwork but through redundancy and approximation." 5 This apparently innocent characteristic of the digital objects has for the author, important unintended consequences to the design process. In another key point, the historian describes, with an analogy that parallels to computer game theory, the notions of the author and the interactor to depict the two levels that all digital objects assume through their generative formulation. The author-main author- defines the overall system, and the interactor, who is to be considered a secondary author, works only with the open variable parameters set forth by the main author. Through these two figures, he investigates different strategies undergone by the design community with regards to the notion of authorship. In one of these strategies, for example, the main author would propose a basic generic model, and the interactor is the agent that would complete or determine the ending aspects of that said model.

One recurrent case study under this category can be found in an urban zoning document which includes a series of regulatory parameters that belong to an organization stipulated by a main author, in this case, the city. To a large extent, these parameters participate in the generic formal definition of the buildings in an urban context. The author, in this case, is diffuse -a group of experts is selected by a corresponding group of controlling agents in each city-. The interactors, on the other hand, are concrete -the builder or the architect who "completes" the generic volume-. Any urban zoning document aims to impose form-based codes -FBCs-, having the number of their definitive parameters increased considerably over time. This higher level of specificity in the generic model has influenced not only the external form of the building but also the program, the distribution of the interiors or the finishing aspects of the building, to name some potential attributes. These control mechanisms tend to happen with greater intensity inside urban limits, given that these are areas with a higher density of population, and in consequence, a greater frequency in the utilitarian interactions among their populations. While performing under such environments, the responsibilities faced by the contemporary architect, have been reduced, except for a small number of examples, to adjusting as an interactor, a model with a theoretical premise already silenced at the starting point of its design process. This sheds light into the contemporary design scene, where the main launching platform for theoretical arguments is found in non-permanent architectures such as interior design projects, temporary installations, pavilions, exhibitions, artifacts or wearable architectures to name some disciples. At the same time, substantial architecture theory potentials should indeed arise from the discipline of urban 


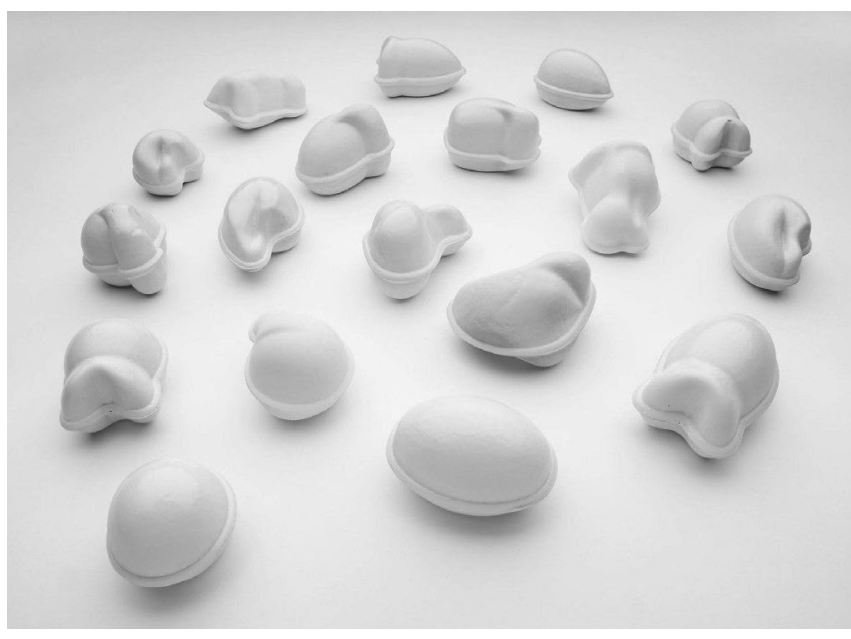

Figure 1: Embryological House, 1997-2001. Greg Lynn, Embryological House: Size "A" eggs, ca. 1999. CCA. "Embryological House." CCA, www. cca.qc.ca/en/issues/4/origins-of-the-digital/5/embryologicalhouse.

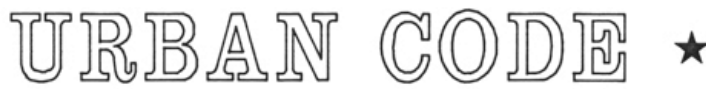

\section{TYPE II RETAII \& OFFICE}

$\star$
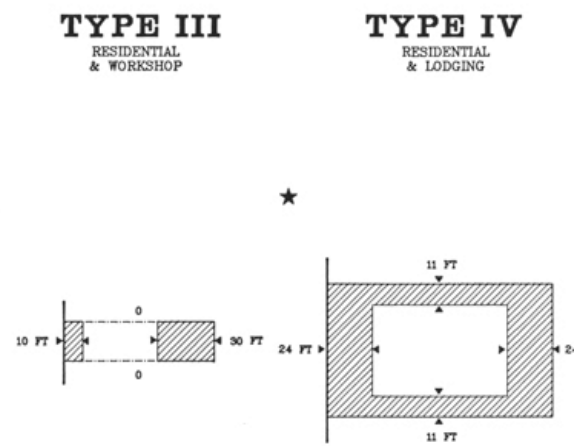

Widne $100 x$ vax

$\star$

WDTH $100 x$ vax

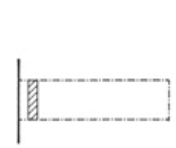

$$
\text { DEPTH on } \operatorname{xix}
$$$$
\text { NDTH } 40 x \text { MES }
$$

$\star$

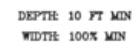

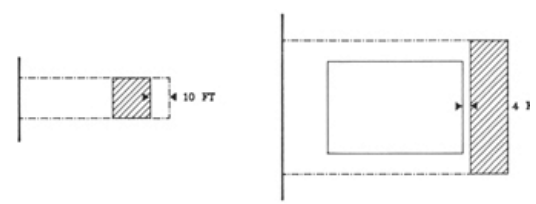

AREA $200 \mathrm{sQ} r \max$

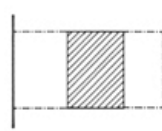

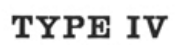
RESIDENTIAL

$\star$

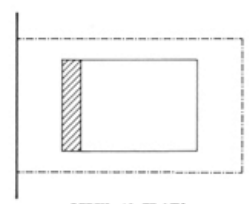

DEPTE $10 \mathrm{rT} \mathrm{\textrm {MN }}$

AREA $800 \mathrm{sQ} n \mathrm{nax}$

Figure 2: Seaside Urban Code. Duany, A. \& Plater-Zyberk, E. 1986

planning, given that these studies have also increased their relevance to the disciple as before demonstrated. Thus, there is a need to research on more flexible organizational systems at the scale of the city to better orient architecture proposals towards more fruitful and thoughtful social, political and economic projects. Architecture, therefore, seems to be trapped inside and in between these two active and decisive realms; both having a strong pulse and a tendency to tame architecture speech and its inherent manifesto.

A parallel analysis to the concept of split authorship explained in Mario Carpo's The Craftsman and the Curator, regards to the methods, times and agents involved in the design construction during its conception and development phases. In the same article, the author proposes a link between the medieval craftsmanship beloved by John Ruskin during the XIX century, and the present figure of the digital craftsman, as they both share the previously mentioned rickety characteristic in their basic structural logic. In his 1849, The Seven Lamps of Architecture, ${ }^{6}$ Ruskin argued that the technical innovations of architecture since the Renaissance and particularly the Industrial Revolution had subsumed its spiritual content and sapped its vitality especially. ${ }^{7}$ This is truer regarding the lamps of 'Truth' and 'Life' as they advocated a building design made by human hands so that the joy of masons and stone carvers would be associated with their expressive -and imperfect-freedom. While there are important distinctions to be made, the digital object is also known to pronounce itself against inaccuracy and imperfection throughout the creative process by performing in perpetuity against its unfinished nature -as if it were in a permanent beta phaseIn that sense, the evolution of an algorithm develops necessarily towards ensuring and safeguarding the continuity of the process and seeks to efficiently repel accidents, misunderstandings or difficulties. Thus, an optimal digital entity is one in which all the drawbacks are planned concurrently with the feedbacks that originate from its usage.

The notion of split authorship is also found in Vitruvius first book of De Architectura 'On the Training of Architects.' The Roman thinker wrote the following regarding technology and architecture: "The science of the architect depends upon many disciplines and various apprenticeships which are carried out in other arts. His personal service consists of craftsmanship and technology. Craftsmanship is continued and familiar practice, which is carried out by the hands in such material as is necessary for a design. Technology sets forth and explains things wrought in accordance with technical skill and method, so architects who without culture, aim at manual skill cannot gain a prestige corresponding to their labors, while those who trust to theory and literature obviously follow a shadow and not a reality. But those who have mastered both, like men equipped in full armor, soon acquire influence and attain their purpose. ${ }^{8}$ Here, Vitruvius hints first to the idea of architecture as a science which depends on a wide variety of disciplines 

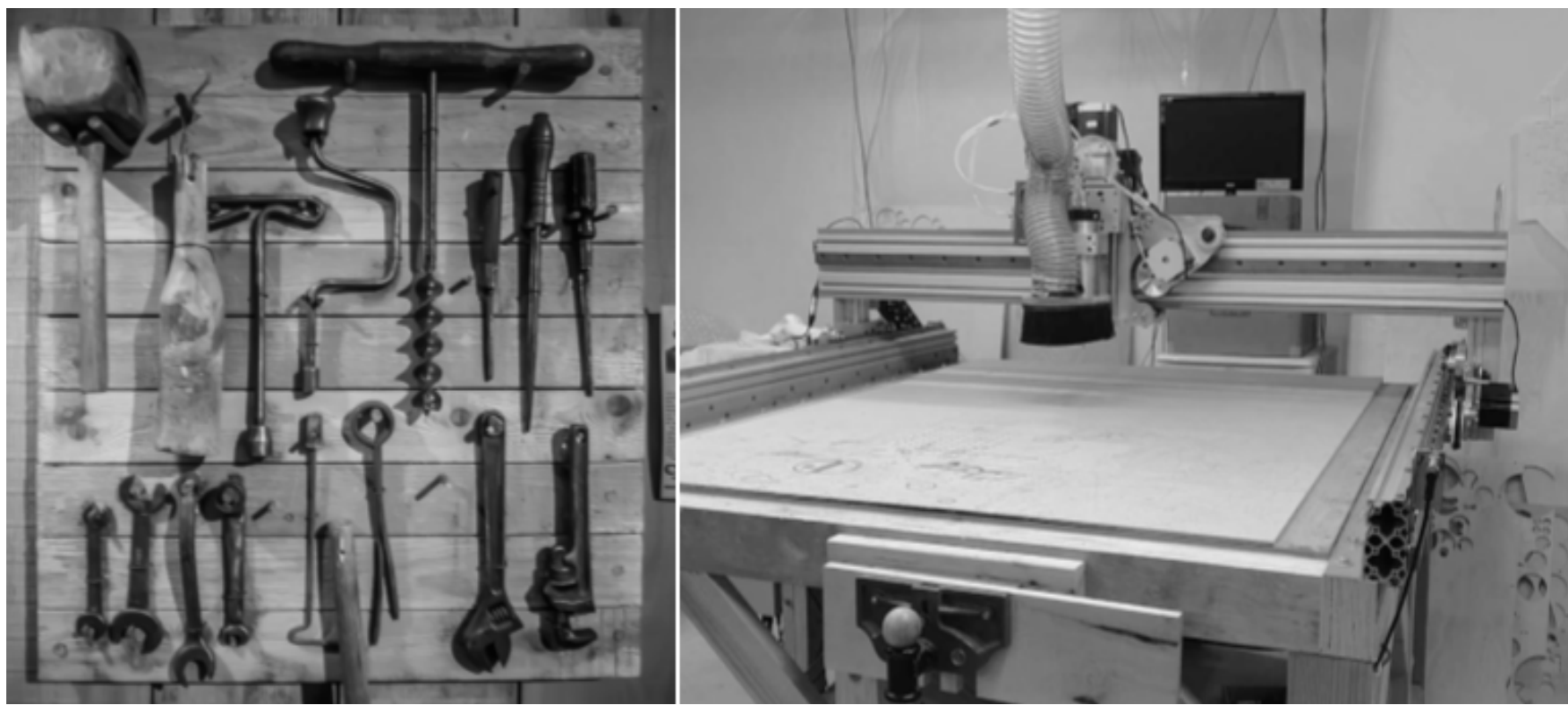

Figure 3 (left): Old Farm Tool Set. Grichenko, Alex. “Old Farm Tool Set Free Stock Photo - Public Domain Pictures." Free Stock Photo - Public Domain Pictures. Figure 4 (right): Build Your Own CNC Machine, Rick's CNC. “Build Your Own CNC Machine - How Much Did It Cost?” YouTube, YouTube, 13 May 2017, www.youtube.com/watch?v=LG8I7q1paW8.

and apprenticeships. Secondly, he advises against the separation of theory and skill thus attaining an architecture purpose when both are mastered. Like in Vitruvius writings, we can find in architecture's history, various levels of intensities regarding control within the discipline's agency on the one hand and to the alignment between skill and theory on the other. This shifting condition has prompted continuous discussions related to the influence of technology in architecture theory and to the impact of the architectural principles onto the technologies of the time. By doing so, two figures became noticeable in Vitruvius' text: the figures of the architect as a manager and the architect as a craftsman. A disciplinary distinction that has had varying connotations in different times and that even today conforms with the arguments behind the architect as a specialist or a generalist. This dual notion has been expressed in accordance with the working relationships that have mutated given the technical specificities of the time. Eventually, behind this diverging pair of agents, the coordination of the architect's capacity to assume or delegate control of the design process is found.

In addition to Mario Carpo's understanding of design as pure information, design processes also tend to secure the continuity of its information parsing and development -whether economic, social, political, technical, etc.-. This is done through the introduction of an administrator expert, the digital manager. In this sense, while the internet has helped architects increase their resource pool and their production speed, it has also facilitated companies' tendency to outsource their subsidiary tasks. The progression associated to the production of architecture has relied fundamentally on the managing and controlling of the multiple layers of information that necessarily overlap but do not evidently influence each other, at least from a disciplinary concern. Consequently, the design process today has fragmented architecture functional organs into distinct parts as if they belonged to different bodies. An action that sparked when the postmodern critical approach gained purchase in the 1980s and 1990s and had been adopted in architecture and many other academic and theoretical disciplines. The digital manager today perpetuates this disintegration process by first separating and cataloging the different building organs and then by reshuffling them according to principles oftentimes unrelated to design itself. With the curator in mind, Carpo understands an optimistic figure in his The Craftsman and the Curator, whose task is to control and organize the pieces made by the digital craftsman. In addition to these figures of the digital craftsman and the curator, one could argue the existence of the digital manager as here introduced. The skills of this agent often overlap with the curator's, even though the former oversees the development of the project with a fundamentally economic, but also social and political awareness. The digital craftsman, on the other hand, operates thanks to the high level of fragmentation in the architecture production and supplies the digital manager with conceptual and material sub-systems. The architect as a digital craftsman underlines a simple disciplinary principle: to understand architecture as a framework of parts that come together into a final product. Her focus is not concerned with architecture's core definition and therefore eludes a theoretical entitlement to it.

In summary, theoretical experimentation in architecture production is being threatened from two different scales: On the one hand, from the scale of the city ordinance as a 


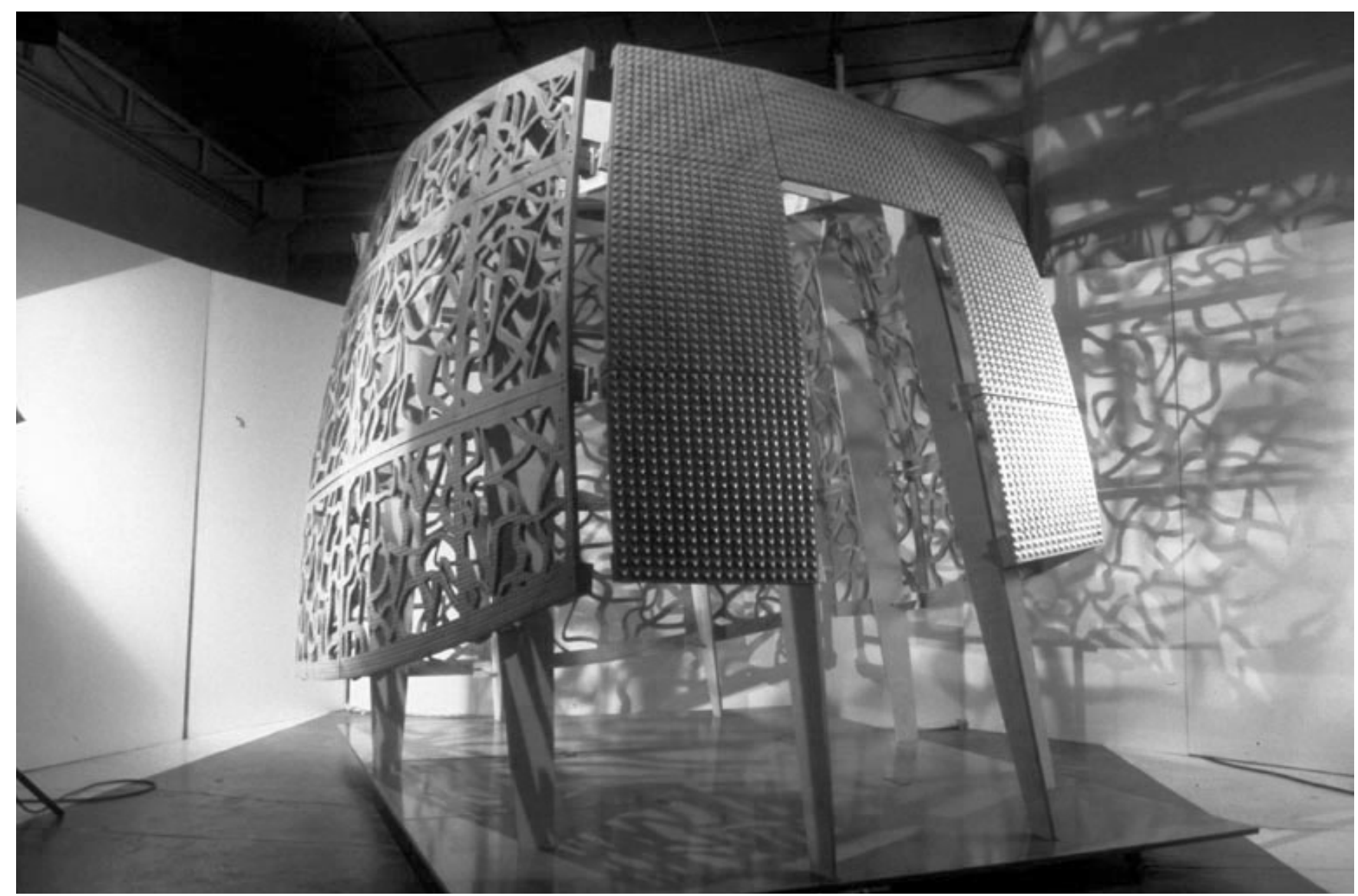

Figure 5: Pavilion Philibert de l’Orme. 2001. Bernard Cache

main author comprising of a parametric system that imposes a generic model in constant expansion of its specificity. And on the other hand, from the scale of the building unit, which is being fragmented into distinct and optimized parts. These parts are thought out and produced by the digital craftsman first and arranged by the digital manager after; a proxy whose preoccupations reside outside the architecture discipline. This fragmentation promotes and symptomizes at the same time a new type of design polarization. One where the design 6 . agents involved in the making of its informational structures are bound by rickety and optimization protocols.

Under this scenario, the ignition of significant urban experimentations is under arrest by forces exterior to the architecture disciple. As Kenneth Frampton pointed out, "today the practice of architecture seems increasingly polarized between on the one hand a so-called 'high-tech' approach predicated exclusively upon production and on the other hand the provisions of a compensatory facade to cover up the harsh realities of this universal system." ${ }^{\prime 9}$

\section{ENDNOTES}

1. Carpo, Mario. The Alphabet and the Algorithm: Form, Standards, and Authorship in times of Variable Media. Cambridge, MA: MIT Press, 2011.

2. Carpo, Mario. The Digital Turn in Architecture 1990-2010. Chichester: Wiley, 2012.

3. Mario Carpo, "The Craftsman and the Curator," Perspecta Vol. 44, Domain (2011): pp. 86-91, 199-200.

4. Carpo, "The Craftsman and the Curator," 87.

5. Carpo, "The Craftsman and the Curator," 91.

Ruskin, John. The Seven Lamps of Architecture; Lectures on Architecture and Painting; The Study of Architecture. Boston: Estes and Lauriat, 1912.

7. Curl, James Stevens. A Dictionary of Architecture and Landscape Architecture. Oxford: Oxford University Press, 2006.

8. Pollio, Vitruvius. Vitruvius: The Ten Books of Architecture. New York: Dover Publications, 1960.

9. Kenneth Frampton, "Prospects for a Critical Regionalism." Perspecta 20 (1983): 17 . 